\title{
On the Development of Reading Ability
}

\author{
Guoqiang Liao \\ Sichuan University of Science \& Engineering, Zigong, 643000, China \\ Email: gqliao408@yahoo.com.cn
}

\begin{abstract}
English reading is not only the purpose of the study, but also the main means and paths of learning English. English reading skill is one of the important language skills, which students have to master. Therefore, in order to improve students' reading ability, teachers should particularly focus on the development of students' effective reading skills and good reading habits.
\end{abstract}

Index Terms—reading ability, skill, habit

\section{INTRODUCTION}

The objective of College English teaching is to develop students' ability to use English in an all-round way, especially in listening and speaking, so that in their future work and social interactions they will be able to exchange information effectively through both spoken and written channels. However, a good reading ability is necessary for students to learn English well. Reading is an important way of gaining information in English language learning. It's a basic skill for a foreign language learner.

Students learn reading to solidify and extend basic knowledge, and develop the lingual basic skills of listening, speaking, reading and writing. So fostering good reading ability is a leading task of learning English. The key of reading is comprehension. Reading comprehension means extracting the required information from the material as efficiently as possible. In order to get the information you need from what you read, you must be able to read both accurately and quickly. A good reader is an accurate and fast reader. For example, there are lots of reading exercises in different types of examinations today. But all these readings must be done in limited time. So students are asked to read them correctly and at a certain speed. To do this, slow students should change their reading skills, reading habits, and enlarge English knowledge.

\section{EFFICIENT READING SKILLS}

In today's fast-paced information age it is simply not good enough to be an $\boldsymbol{O K}$ reader. It is more important than ever to have efficient reading skills. It is interesting to note that efficient readers are not only reading faster, but they are also reading with better comprehension. An efficient reader has learned the art of reading text in much the same way that most of us look at objects in the world around us. When an efficient reader comes across the word "blue", they don't repeat the word "blue" to themselves, then think about the meaning. Instead, an efficient reader will understand and visualize the color much in the same way most people do when they look up at a blue sky. When you look up at a blue sky, you are typically not saying "blue sky", then thinking about the meaning, but instead you simply absorb the meaning immediately and effortlessly.

Efficient reading requires the use of various problem-solving skills such as holding the main idea of an article, understanding facts and details, guessing unknown words, making inferences and so on. Among them word-guessing skill is one of the most important. No matter how large your vocabulary is, it is impossible for you to know the meaning of every word you read. Even if you are allowed to look them up in a dictionary, you not only slow down your reading speed but also interrupt your thinking. Therefore, you have to deduce the possible meanings of unfamiliar words by using context clues or word analysis.

\section{A. Using the Context}

Context refers to the sentence and paragraph in which a word occurs. In using the context to decide the meaning of a word you have to use your knowledge of grammar and your understanding of author's ideas because they can indicate the relationships among parts of the sentence and the paragraph. Thus, the other words in the sentences that come before and after can often help you to guess the meanings of the unfamiliar words by providing a definition, an example, a restatement, a synonym or an antonym. Such as "means", "refer to", "unlike", "however", "on the other hand", "on the contrary ", "in other words", "furthermore", "in fact", "consequently" are all the hints.

Another way to determine the meaning of an unfamiliar word is word analysis. That is, looking at the meanings of parts of words. Many English words have been formed by combining parts of older English, Greek and Latin words. If you know the meanings of these words' parts, you can often guess the meaning of an unfamiliar word, particularly in context.

\section{B. Using a Dictionary}


There are some cases in which you can find very few context clues to use or there are too many new words to guess that you have to go to a dictionary. Besides it is also necessary for you to consult a dictionary after finishing reading in order to make sure you understand the exact meaning and usage of the unfamiliar words. Only in this way can you really grasp the words and make them become your active vocabulary.

A good dictionary provides lots of information about a word: spelling, pronunciation, part of speech, definitions, example sentences, derivations, and phrases etc. Some even provide usage labels, origin of the word, synonym or antonym, how frequently the word is used and so on. Almost every English word has more than one single meaning. In order to quickly locate the right meaning you should first have a rough idea of what part of speech it belongs to. After that you can scan the dictionary to find the right meaning. When you are not quite sure whether you have found the right one or not, the example sentences can often help you. Sometimes you can find some words used together in a sentence whose meaning cannot be understood from the ordinary meanings of the words in it. These words probably are an idiom or a set phrase. In this case you should decide the key word in the idiom and look it up in the dictionary.

Nowadays some students prefer an electronic dictionary to a paper one, because they think it is operated very conveniently and quickly. However, they don't realize that the paper dictionary usually provides more information of a word than an electronic one, and the process of consulting a paper dictionary is a very helpful way to develop scanning ability. Thus you should keep the habit of using a paper dictionary when possible.

\section{Scanning Skill}

Scanning is a technique you often use when you search for key words or ideas. In most cases, you know what you're looking for, so you're concentrating on finding a particular answer. Scanning involves moving your eyes quickly down the page seeking specific words and phrases. Scanning is also used when you first find a resource to determine whether it will answer your questions. Once you've scanned the document, you might go back and skim it. When scanning, look for the author's use of organizers such as numbers, letters, steps, or the words, first, second, or next. Look for words that are bold faced, italics, or in a different font size, style, or color. Sometimes the author will put key ideas in the margin.

\section{Skimming Skill}

Skimming is used to quickly identify the main ideas of a text. When you read the newspaper, you're probably not reading it word-by-word, instead you're scanning the text. Skimming is done at a speed three to four times faster than normal reading. People often skim when they have lots of material to read in a limited amount of time. Use skimming when you want to see if an article may be of interest in your research.

There are many strategies that can be used when skimming. Some people read the first and last paragraphs using headings, summarizes and other organizers as they move down the page or screen. You might read the title, subtitles, subheading, and illustrations. Consider reading the first sentence of each paragraph. This technique is useful when you're seeking specific information rather than reading for comprehension. Skimming works well to find dates, names, and places. It might be used to review graphs, tables, and charts.

\section{E. Making Inferences}

If you want to accurately understand an article, you should make correct inferences. Sometimes, the author is describing a certain matter or discussing a certain problem, while he doesn't tell us the answer. Then you should make inferences according to the contents and the general knowledge that you already have. To make the result correct, you must focus on the topic, the fact and proofs that the article has provided.

\section{F. Using the Title}

Reading is an interactive process -- it is two-way. This means you have to work at constructing the meaning from the marks on the paper. You need to be active all the time when you are reading. It is useful, therefore, before you start reading to try to actively remember what you know, and do not know, about the subject and then formulate questions based on the information you have. You can then read to answer these questions. Title, sub-titles and section heading can help you formulate questions to keep you interacting. The title is a summary of the text. Sometimes we have to make quick decisions based on only the title. Therefore it is useful to try to understand it well. This may mean looking up unfamiliar words in a dictionary.

It is a good idea to ask yourself the following questions, based on the title.

Is this text relevant to your needs? Is it related to the subject you are studying?

What do you expect to learn from the text? Ask yourself some questions that you expect the text to answer.

\section{IMPROVING READING ABILITY}

\section{A. Reading Habits}

If you want to raise your reading efficiency, you should pay attention to your reading habits.

Someone reads word by word, or someone reads with his finger pointing to the words or with his head shaking. Those are all bad habits. You should read phrase by phrase. Don't blink your eyes so often and don't shake your head. Just move 
your eyeball. That's enough. If you want to get more word information, there must be a proper distance between your eyes and the reading materials.

\section{B. Extensive Reading}

Extensive reading is one of the ways of teaching reading. According to Richards and Schmidt (2002, p. 193), "extensive reading means reading in quantity and in order to gain a general understanding of what is read." Thus, although there are variations in the ways in which an extensive reading programme is administered, extensive reading programmes share the basic tenet that students read a relatively large amount of texts compared with what is called intensive reading, which usually involves a slower reading of a relatively small amount of materials and often with translation exercises, particularly in a foreign language situation. In extensive reading programmes, students read relatively simpler materials than in intensive reading programmes, and they are not usually required to demonstrate understanding to a degree as detailed as they would in intensive reading programmes. Instead, students are expected to read a large amount of texts while enjoying reading. Extensive reading, as partly mentioned above, "is intended to develop good reading habits, to build up knowledge of vocabulary and structure, and to encourage a liking for reading" (Richards and Schmidt, 2002, p. 193-194).

\section{Basic Conditions for Increased Reading Rate}

A well planned program prepares for maximum increase in rate by establishing the necessary conditions. Four basic conditions include: Have your eyes checked. Before embarking on a speed-reading program, make sure that any correctable eye defects you may have are taken care of by checking with your eye doctor. Often, very slow reading is related to uncorrected eye defects. Eliminate the habit of pronouncing words as you read. If you sound out words in your throat or whisper them, you can read slightly only as fast as you can read aloud. You should be able to read most materials at least two or three times faster silently than orally. If you are aware of sounding or "hearing" words as you read, try to concentrate on key words and meaningful ideas as you force yourself to read faster. Avoid regressing (rereading). The average student reading at 250 words per minute regresses or rereads about 20 times per page. Rereading words and phrases is a habit that will slow your reading speed down to a snail's pace. Usually, it is unnecessary to reread words, for the ideas you want are explained and elaborated more fully in later contexts. Furthermore, the slowest reader usually regresses most frequently. Because he reads slowly, his mind has time to wander and his rereading reflects both his inability to concentrate and his lack of confidence in his comprehension skills. Develop a wider eye-span. This will help you read more than one word at a glance. Since written material is less meaningful if read word by word, this will help you learn to read by phrases or thought units.

\section{Comprehensive Knowledge}

Besides those skills mentioned above, to improve reading ability, we should enlarge students' comprehensive knowledge about English. Encourage students to read something in their spare time about novel, play, biography, poem, history, culture, story and so on. For example, there are two pieces of materials of the same difficulty. One explains something about China's Spring Festival; the other is about Thanksgiving Day of the western countries. The former is easy to understand but the latter is more difficult. Why? It is clear that students know little about the latter. There are many foreign articles, from which we can know a lot about the flavors of English-speaking countries. So you must read lots of classical model essays, and recite some excellent texts, wonderful paragraphs or sentences, and accumulate a large of English materials, phrases, idioms, fixed sentence patterns and habitual expressions, then you can express them with your own words or even rewrite them.

\section{CONCLUSION}

To improve reading ability efficiently, you should develop some good reading skills in the first place. Secondly, you must have good reading habits. Thirdly you need to know well about the questions of reading comprehension and enlarge your English knowledge. Finally, there are different styles of reading for different situations. The technique you choose will depend on the purpose for reading. For example, you might be reading for enjoyment, information, or to complete a task. If you are exploring or reviewing, you might skim a document. If you're searching for information, you might scan for a particular word. To get detailed information, you might use a technique such as SQ5R. You need to adjust your reading speed and technique depending on your purpose. As long as you insist on using scientific skills, reading every day, and summing up continuously, the efficient reading ability is not difficult to be achieved.

\section{REFERENCES}

[1] Richards, J. C. \& Schmidt, R. (Eds.). (2002). Longman dictionary of language teaching and applied linguistics (3 ${ }^{\text {rd }}$ ed.). London: Longman.

[2] Mills, G.E. (2000). Action research: A guide for the teacher researcher. Upper Saddle River, NJ: Merril.

[3] Strickland, D.S., Ganske, K., \& Monroe, J.K. (2002). Supporting struggling readers and writers. Portland, ME: Stenhouse.

[4] Walker, B.J. (2000). Diagnostic teaching of reading: Techniques for instruction (4th ed.). New York: Longman.

[5] Devlin, JT. (2006). The role of the posterior fusiform gyrus in reading. Journal of cognitive neuroscience 18 (6): 911-22.

[6] Coleman C, Lindstrom J, Nelson J, Lindstrom W, Gregg KN (2010). Passageless comprehension on the Nelson-Denny reading 
test: well above chance for university students. J Learn Disabil 43 (3): 244-9.

Guoqiang Liao was born in Zigong, China in 1965. He received his M.A. degree in linguistics from Southwest University, China in 1997.

$\mathrm{He}$ is currently a teacher in the School of Foreign Languages, Sichuan University of Science \& Engineering, China. His research interests include English language and culture.

Mr. Liao is a member of Sichuan Translators Association. 